http://jmscr.igmpublication.org/home/ ISSN (e)-2347-176x ISSN (p) 2455-0450 crossref DOI: https://dx.doi.org/10.18535/jmscr/v9i6.04

\title{
Study of Lipid Parameters in Ischemic Stroke Patients
}

\author{
Authors \\ Arvind Kumar*, Prem Singh**1, Gaurav Gupta***, Brijesh Kumar*, \\ Mahendra Singh**2 , S.K. Gautam*, Tanu Midha*3 \\ *Associate Professor of Medicine ${ }^{*}{ }^{3}$ Associate Professor of SPM $* *{ }^{1}$ Professor of Medicine \\ $* * 2$ Professor and Head of Pathology ***Junior Resident of Medicine
}

GSVM Medical College, Kanpur

Corresponding Author

Gaurav Gupta

\begin{abstract}
Background: Stroke is one of the most frequent causes of death and disability worldwide with a significant clinical and socioeconomic impact. The objectives were to know whether there is a role for dyslipidemia in the occurrence of ischemic strokeand if there is any difference in the various lipid parameters of the case and control groups.

Aims and Objective: To determine the role of lipid parameters on the occurrence of ischemic stroke and its comparison with age and sex-matched controls.

Material and Methods: A case-control study was done and a total of 48 patients with acute ischemic stroke were chosen. An equal 48 controls were included in this study for the comparison of outcome. A serum sample after 8 hours of overnight fasting was taken on the next day of admission for both groups of patients. Total serum cholesterol, triglycerides, LDL-cholesterol, and HDL-cholesterol were determined, using the enzymatic colorimetric method.

Results: In 48 ischaemic stroke patients, raised serum total cholesterol was seen in 11, triglyceride in 15 and LDLcholesterol in 16 patients. On the other hand, raised serum total cholesterol observed in 10, triglyceride in $12, L D L-$ cholesterol in 12 age and sex matched 48 control subjects. Serum HDL-cholesterol was below the normal reference in 09 cases and 04 controls subjects. On comparison, no statistical significance was found on comparing abnormal values of both groups for total cholesterol, triglycerides, $L D L-C$ and $H D L-C$. Also after comparing mean values for different lipid parameters no significant association observed in our study.

Conclusion: We found that lipid profile values are not associated with an increased risk of ischaemic stroke.

Keywords: Diabetes, Dyslipidemia, Infarct, Ischemia.
\end{abstract}

\section{Introduction}

Stroke is a global health problem. It is one of the most frequent causes of death and disability worldwide with an enormous significant clinical and socioeconomic impact. It is a leading cause of functional impairments, with approximately $20 \%$ of patients requiring institutional care after 3 months and $15-30 \%$ being permanently disabled. ${ }^{1}$ The WHO has defined stroke or cerebrovascular disease as a syndrome of rapidly developing clinical symptoms, with an apparent vascular cause, of focal or global disturbance of cerebral function lasting for $\geq 24$ hours or leading to death. ${ }^{2}$ On the cellular level, in the ischemic neuron, the membrane ion-transport system is not able to function properly due to depletion of ATP. Impairment of cellular metabolism also disrupts normal sodium-potassium plasma membrane pumps, results in an intracellular increase in sodium, which in turn drags water along with it 
leads to an increase in intracellular water content. This cellular swelling is referred to as cytotoxic edema and develops very early in cerebral ischemia. $^{3}$

Ischemia also directly results in dysfunction of the cerebral vasculature, with disruption of the bloodbrain barrier occurring within 4-6 hours postinfarction. Following the barrier's breakdown, proteins and water flood into the extracellular space resulting in vasogenic edema. This produces greater levels of brain swelling and mass effects that peak at 3-5 days and resolve over the next several weeks with resorption of water and proteins. $^{4}$

The incidence and mortality of stroke vary greatly among different populations Although stroke mortality has declined to $40-60 \%$ within the U.S. and other developed countries because of strict blood pressure level control, the burden of stroke continues to be rising because of a rise within the olderpopulation ${ }^{5,6}$ Likewise, the increased survival rate in developing nations has led to rising stroke prevalence in middle-income countries. ${ }^{5,6}$ This might be explained by the fast pace of urbanization and also the overall increase in the elderly population because of increased longevity. ${ }^{6}$

There are various non-modifiable risk factors such as age, gender, familial trends, race, and ethnic groups and modifiable factors such as hypertension, cardiac disease, diabetes mellitus, dyslipidemia, smoking, alcohol abuse, sedentary lifestyle, asymptomatic carotid stenosis, and TIAs. The traditional risk factors for both coronary artery disease and stroke are smoking, diabetes, hypertension, and dyslipidemia. ${ }^{8}$ But unlike in coronary artery disease the evidence for the role of these risk factors in stroke is less convincing especially dyslipidemia. ${ }^{9}$ Austin, et $\mathbf{a l}^{\mathbf{1 0}}$ first described the term atherogenic dyslipidemia. Itsspectrum consists of high LDLcholesterol, high triglyceride, and low HDLcholesterol. $^{10}$ Whether dyslipidemia is a risk factor for stroke is debatable. One of the reasons why the role of lipids is controversial might be because most studies club together ischemic and hemorrhagic stroke. The combination of negative association with hemorrhagic stroke and positive association with ischemic stroke might mask the positive influence when considering stroke as one entity. $^{11}$

Despite the controversies, many meta-analyses estimated that statin therapy results in a $24-29 \%$ reduction in stroke-related mortality especially ischaemic subtype over a wide range of lipid values. ${ }^{12}$ There is an increasing prevalence of conditions like diabetes, hypertension, obesity, and dyslipidemia in India. This has also led to an increase in the burden of coronary artery disease and cerebrovascular disease. ${ }^{13}$ This has a major social impact in a country like India. Hence, we must have a thorough understanding of the risk factors for stroke and the ways of preventing the occurrence of stroke. We conducted this study in the background of such conflicting information. The objectives were to know whether there is a role for dyslipidemia in the occurrence of ischemic stroke.

\section{Aims and Objectives}

To study serum lipid parameter levels in patients with ischaemic stroke and compare them with age and sex-matched control to find out any significant correlation.

\section{Materials and Methods Study design}

We conducted a case-control study over one and half years (January 2019 to October 2020). The study was conducted at the department of internal medicine, GSVM Medical College Kanpur, and subjects were recruited from Medicine Emergency and wards. The study was approved by the Ethics Committee of the institute ETHICS APPROVAL NUMBER (EC/BMHR/211/OCT/2020, dated 23/10/2020).

\section{Participants}

A total of 48 patients with acute ischemic stroke were chosen in the study. An equal 48 healthy controls were taken from normal healthy 
individuals attending medicine OPD/SEMIEMERGENCY. One case will be taken for each control for comparison of outcome. Informed consent subjects with Age >18 years both genders with ischemic cerebrovascular accident identified based on clinical as well as laboratory and radiological evaluation (including $\mathrm{CT} / \mathrm{MRI}$ ) admitted in our hospital were included in our study. Subjects with a previous history of TIA/CVA, on vitamin D and calcium supplementation, lipid-lowering drugs, CKD, CLD, DIABETES MELLITUS, patients who underwent thrombolysis, cardio-embolic stroke patients were excluded from the study.

\section{Procedure Methodology}

All the required details about cases such as demographic data (age, gender, address, registration number, etc), clinical presentations (signs \& symptoms), general examination findings, systemic examination, and Ischemic stroke findings were carried out. The blood sample was taken from all patients with acute stroke during 24 hours of admission to check serum lipid profile levels, fasting blood sugar,
HbA1c, LFT, KFT, and lipid profile. All patients underwent a CT scan brain (plain) to establish the ischemic lesion if patients had a normal CT scan brain, then ischemic stroke was diagnosed based on diffusion-weighted MRI.

\section{Statistical Analysis}

Data were analyzed using Statistical Package of Social Sciences (SPSS, version 23.0) software and Quantitative data were expressed as mean and standard deviation. Chi-square test was used as a test of significance. Continuous data were analyzed using the student's T-test. Intergroup or intergroup comparisons were done using an independent sample test for comparison of mean values. Association between variables was considered statistically significant if the $p$-value was $<0.05$

\section{Observation and Result}

The mean age of the case group was $60.95 \pm 13.9$ years which is comparable $[\mathrm{p}$ value $=0.937$ (not significant)] to the mean age of the control group which was $61.16 \pm 11.6$ years.

Table No -1 Average Ages Between Cases and Controls

\begin{tabular}{|l|c|c|c|}
\hline & Case $(\mathrm{n}=48)$ & Control $(\mathrm{n}=48)$ & P value \\
\hline Mean Age (in years) & $60.95 \pm 13.9$ & $61.16 \pm 11.6$ & 0.937 \\
\hline
\end{tabular}

\section{Graph No -1}

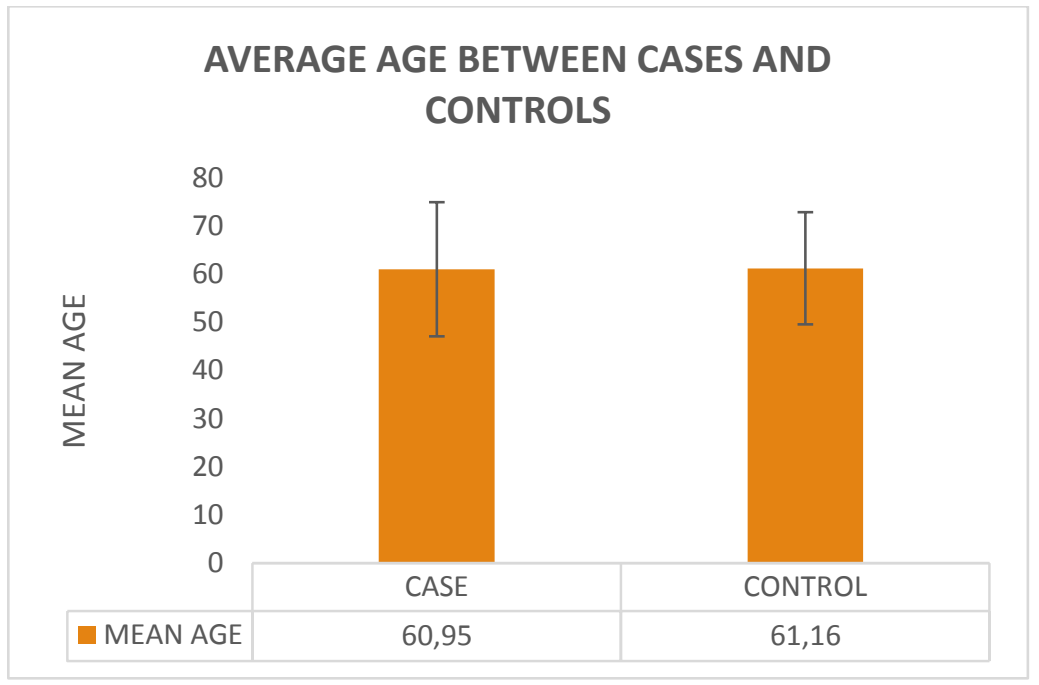




\section{JMSCR Vol||09||Issue||06||Page 16-23||June}

Table 2 Cases and Controls with Respect to total Cholesterol

\begin{tabular}{|l|c|c|c|}
\hline Bio Chemical Parameters & Case $(\mathbf{n = 4 8})$ & Control $(\mathbf{n}=\mathbf{4 8})$ & P value \\
\hline Serum Total Cholesterol $(\mathrm{mg} / \mathrm{dl})$ & $174.37 \pm 51.79$ & $165.16 \pm 47.99$ & 0.369 \\
\hline
\end{tabular}

The mean Total Cholesterol among cases and controls is $174.37 \pm 51.79$ and $165.16 \pm 47.99 \mathrm{mg} / \mathrm{dl}$, respectively. This difference was not statistically significant. $\mathrm{t}=0.903$, df $=94, \mathrm{p}$ value $=0.369$ (not significant)

\section{Graph No-2}

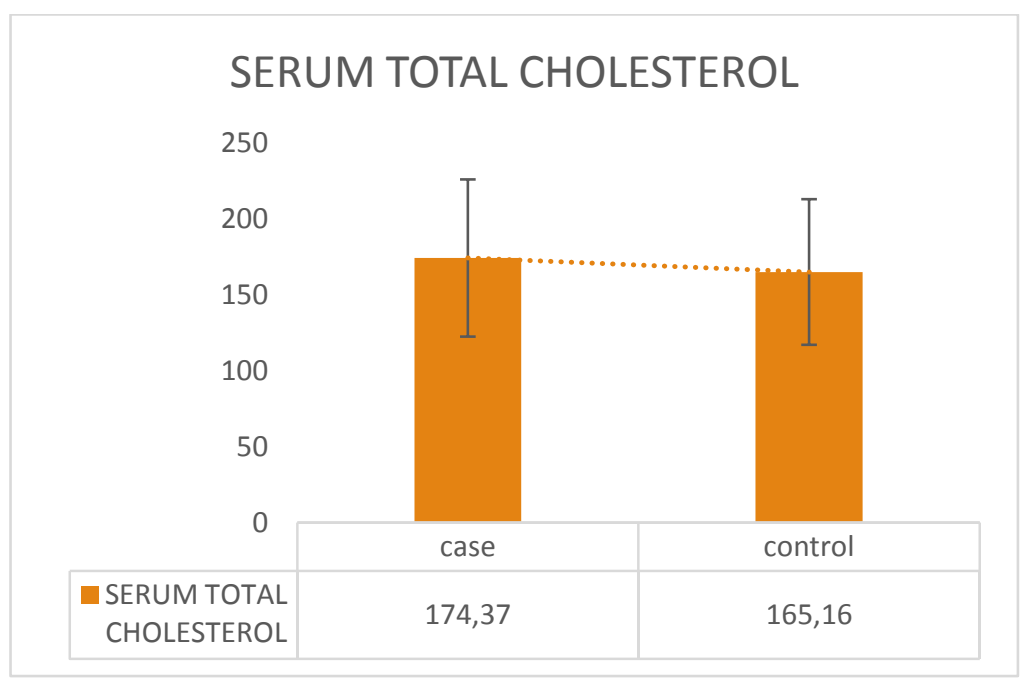

Table 3 Cases and Controls with Respect to Triglycerides

\begin{tabular}{|l|c|c|c|}
\hline Bio Chemical Parameters & Case $(\mathbf{n}=\mathbf{4 8})$ & Control $(\mathbf{n}=\mathbf{4 8})$ & P value \\
\hline Serum Triglycerides $(\mathrm{mg} / \mathrm{dl})$ & $135.10 \pm 38.02$ & $125.29 \pm 42.81$ & 0.238 \\
\hline
\end{tabular}

The mean TG among cases and controls is $135.10 \pm 38.02$ and $125.29 \pm 42.81 \mathrm{mg} / \mathrm{dl}$ respectively, this difference was not statistically significant. $\mathrm{t}=1.187 \mathrm{df}=94, \mathrm{p}$ value $=0.238$ (not significant)

\section{Graph No-3}

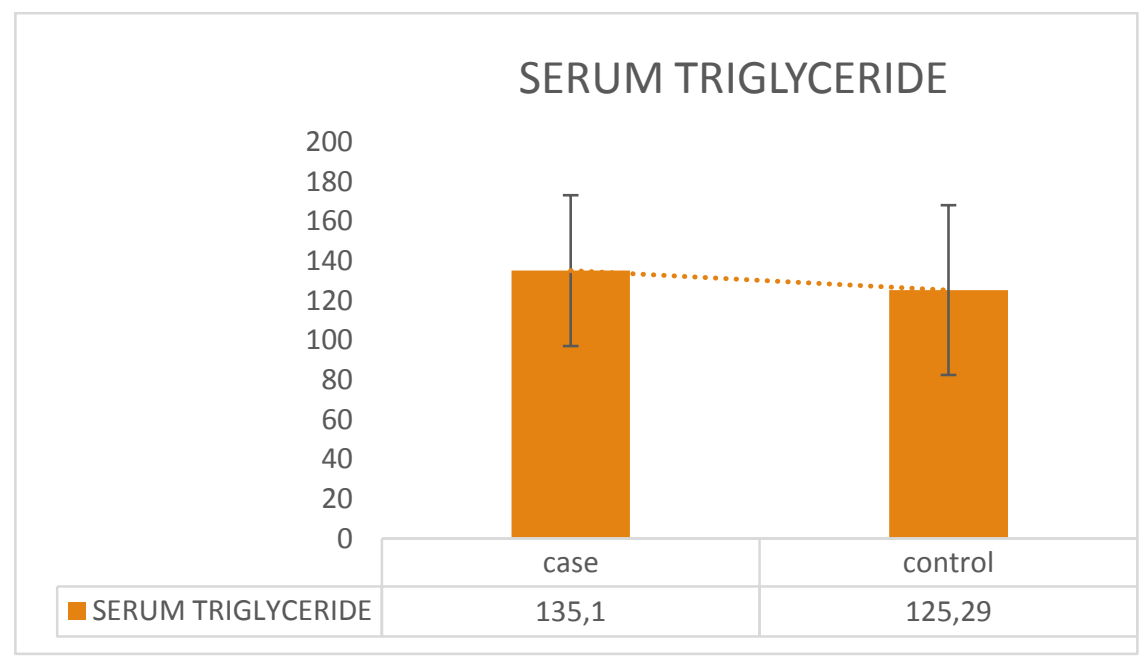


Table 4 Cases and Controls with Respect to HDL-C

\begin{tabular}{|l|c|c|c|}
\hline Bio Chemical Parameters & Case $(\mathbf{n}=\mathbf{4 8})$ & Control $(\mathbf{n}=\mathbf{4 8})$ & P value \\
\hline Serum HDL-C $(\mathrm{mg} / \mathrm{dl})$ & $48.50 \pm 12.26$ & $51.50 \pm 10.81$ & 0.196 \\
\hline
\end{tabular}

The mean HDL-C among cases and controls is $48.50 \pm 12.26$ and $51.50 \pm 10.81 \mathrm{mg} / \mathrm{dl}$, respectively. This difference was not statistically significant. $\mathrm{t}=1.304, \mathrm{df}=94, \mathrm{p}$ value $=0.196$ (not significant)

\section{Graph No-4}

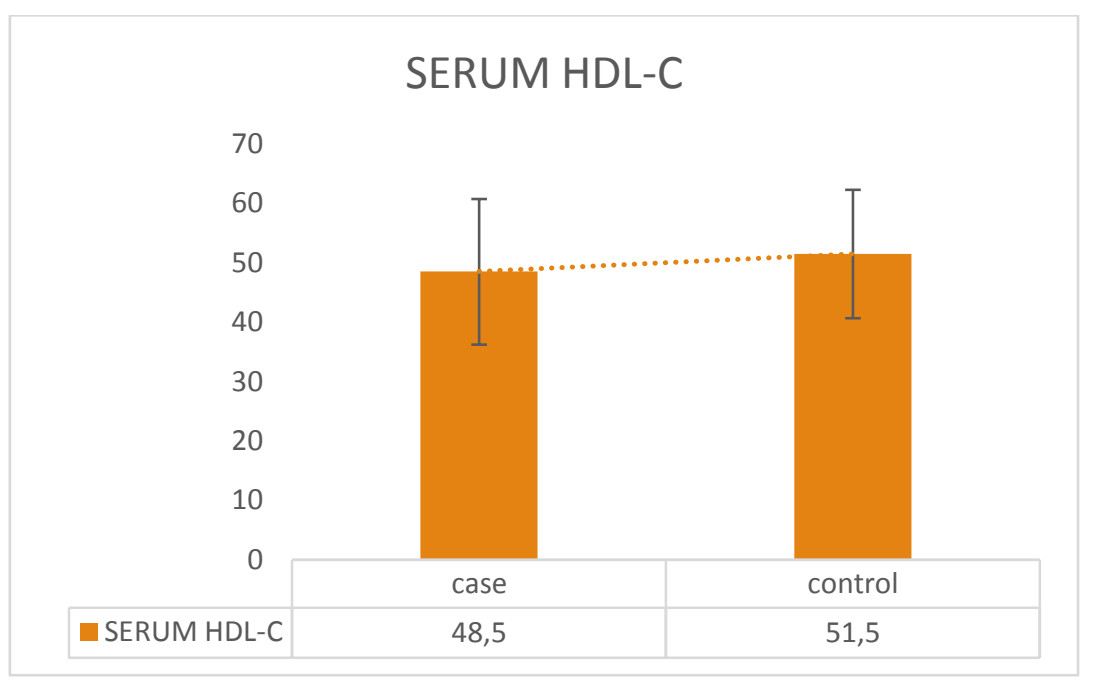

Table 5 Cases and Controls with Respect to LDL-C

\begin{tabular}{|l|c|c|c|}
\hline Bio Chemical Parameters & Case $(\mathbf{n}=\mathbf{4 8})$ & Control $(\mathbf{n}=\mathbf{4 8})$ & P value \\
\hline Serum LDL-C $(\mathrm{mg} / \mathrm{dl})$ & $93.25 \pm 40.92$ & $85.43 \pm 34.45$ & 0.314 \\
\hline
\end{tabular}

The mean LDL-C among cases and controls is $93.25 \pm 40.92$ and $85.43 \pm 34.45 \mathrm{mg} / \mathrm{dl}$, respectively. This difference was not statistically significant. $\mathrm{t}=1.013, \mathrm{df}=94, \mathrm{p}$ value $=0.314$ (not significant).

\section{Graph No-5}

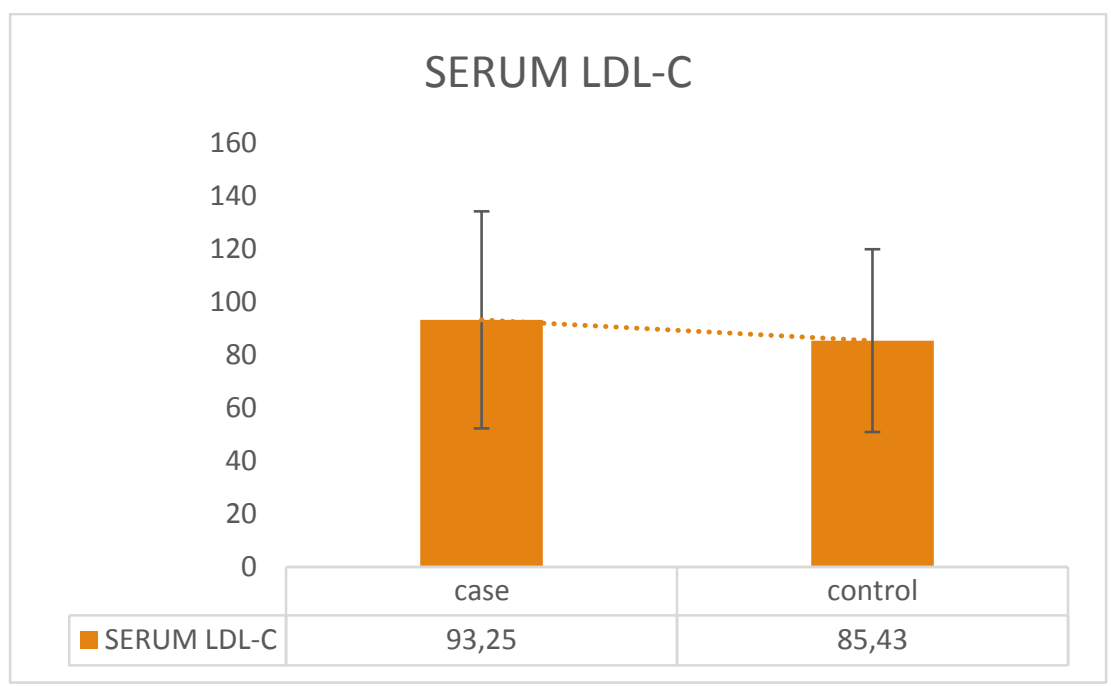


Table-6 Comparison of abnormal lipid profile in case and control patients $(n=96)$.

\begin{tabular}{|l|c|c|c|}
\hline & \multicolumn{2}{|c|}{ cases with abnormal lipid values } & \multirow{2}{*}{ p-value } \\
\cline { 2 - 3 } & Case $(\mathrm{n}=48)$ & Control $(\mathrm{n}=48)$ & \\
\hline Serum cholesterol & 11 & 10 & 0.805 \\
\hline Serum Triglyceride & 15 & 12 & 0.495 \\
\hline Serum HDL-cholesterol & 9 & 6 & 0.399 \\
\hline Serum LDL-cholesterol & 16 & 12 & 0.369 \\
\hline
\end{tabular}

No statistical significance was found on comparing abnormal serum values of Cholesterol, Triglyceride, LDL-C, and HDL-C in the case and control group.

\section{Discussion}

\section{Age and Gender Variation in Both Groups}

In our study, out of 96 study subjects, 48 subjects were in the case group with $29(61 \%)$ males and 19 (39\%) females. Out of 48 subjects of the control group, 28 (42\%) were males and $20(58 \%)$ were females. The mean age of the case group was $60.95 \pm 13.9$ years which is comparable to the mean age of the control group which was $61.16 \pm$ 11.6 years. The age group of both groups is comparable. $[p$ value $=0.937$ (not significant) .

\section{Stroke and Lipid Parameters}

The mean Total Cholesterol among cases and controls is $174.37 \pm 51.79$ and $165.16 \pm 47.99$ $\mathrm{mg} / \mathrm{dl}$, respectively ( $\mathrm{p}$-value $=0.369)$. Hypercholesteremia is observed in 11 and 10 patients in the case and control group respectively. No statistically significant difference was found between both groups. Zhang $\mathrm{X}$, et $\mathbf{a l}^{\mathbf{1 4}}$ (2003) have shown that cholesterol, LDL, and triglyceride are independent risk factors for ischemic stroke. They observed in their study that total cholesterol is strongly associated with the risk of CAD and ischaemic stroke, but not with hemorrhagic stroke. On the other hand, some studies showed that serum cholesterol does not influence the occurrence of stroke as shown by Lindenstrom $\mathbf{E}$ et al $^{\mathbf{1 5}}$ Conflicting results shown in studies about the correlation between the total plasma cholesterol of patients and the risk of stroke. Qizilbash et $\mathbf{a l}^{\mathbf{1 6}}$ in a review of 10 studies examining the relationship between serum total cholesterol and increase risk of stroke concluded that there was a significant association however, other studies were less conclusive.

The mean TG among cases and controls is $135.10 \pm 38.02$ and $125.29 \pm 42.81 \mathrm{mg} / \mathrm{dl}$ respectively, while Hypertriglyceridemia is observed in 15 and 12 patients in the case and control group respectively; we observed no significant association between the two groups( $p$ value $=0.238)$. The Association between concentrations of S.TG and the risk of stroke is also controversial. Some studies led to negative results while others showed a positive association with high S.TG concentrations. ${ }^{17}$ Copenhagen city Heart Study ${ }^{15}$ showed a log-linear association between S.TG concentrations and ischemic stroke while noassociation was found of high S.TG concentration as a risk factor for both types of stroke in this study.

The mean HDL-C among cases and controls is $48.50 \pm 12.26$ and $51.50 \pm 10.81 \mathrm{mg} / \mathrm{dl}$, respectively. while low HDL-C levels $(<40 \mathrm{mg} / \mathrm{dl})$ are observed in 9 and 6 patients in the case and control group respectively. There is no significant association observed between HDL-C and ischaemic stroke in the present study as $20 \%$ of patients with ischaemic stroke had below-normal serum HDL-cholesterol. Serum HDL-C has antiatherogenic properties by carrying cholesterol from peripheral cells to the liver and thus having a protective effect.26 However, recently it has been observed that serum HDL-cholesterol levels decrease significantly at the time of acute ischaemic stroke and it may be an acute phase reactant or nascent biomarker of acute stroke susceptibility. ${ }^{18}$

The mean LDL-C among cases and controls is $93.25 \pm 40.92$ and $85.43 \pm 34.45 \mathrm{mg} / \mathrm{dl}$, respectively. While the increased level of LDL-C $(>100 \mathrm{mg} / \mathrm{dl}$ ) is observed in 15 and 12 patients in 
the case and control group respectively. A positive relationship between high serum LDL-C and other levels and the risk of ischaemic stroke has been seen as well. However, we didn't observe such a relation in our study. This difference was not statistically significant. ( $\mathrm{p}$-value $=0.314)$.

In our patient population, we were not able to demonstrate any correlation between the case and the control group regarding any of the lipid parameters, maybe because the total number of subjects in our study is very low, moreover, in subgroup analysis, the numbers further decrease in our study as compared to the studies which show a positive correlation. In this study, blood samples were collected within 24 hours after admission and there was no follow-up data to indicate the effect of stress or nutrition on those patients, but studies have shown that serum cholesterol measurements within the first 48 hours remain identical to those after three months. ${ }^{19}$ This study, despite its shortcomings, suggests no significant difference between the values of serum total cholesterol and serum HDL-C, S.TG, LDL-C in case and control groups.

We need a large population-based study excluding other risk factors which itself can cause an ischemic stroke to establish a proper association between dyslipidemia and risk of ischemic stroke.

\section{Bibliography}

1. Khan NI, Naz L, Mushtaq S, Rukh L, Ali $\mathrm{S}$, Hussain Z. Ischaemic stroke: prevalence of modifiable risk factors in male and female patients in Pakistan. Pak J Pharm Sci 2009; 22:62-7.

2. World Health Organization. The world health report: shaping the future. Geneva: WHO; 2003

3. Kouna NP, Millogo A, Siemefe KF, Assengone ZY. Epidemiological and progressive aspects of stroke at the Hospital Center of Libreville. African J Neurol Scien. 2007;26:12-7.

4. Hollander M, Koudstaal PJ, ML Bots, Grobbee D, Hofman A, Breteler M.
Incidence, risk and case fatality of ever stroke in the elder population. The Rotterdam study. J neurolneurosurg Psychiatry. 2003 Mar; 74 (3):317-21.

5. Kim AS, Johnston SC. Temporal and geographic trends in the global stroke epidemic. Stroke. (2013) 44: S123-5. DOI:10.1161/STROKEAHA.111.000067.

6. Feigin VL, Norrving B, Mensah GA. Global burden of stroke. Circ Res. (2017) 120:439-48. DOI: 10.1161/CIRCRESAHA.116.308413.

7. Khan J, Attique-ur-Rehman, Ali SA, Jielani A. Frequency of hypertension in stroke patients presenting at Ayub Teaching Hospital. J Ayub Med Coll Abbottabad 2006; 18:59-61.

8. García-Moll X. Inflammation, Atherosclerosis, Classic Cardiovascular Risk Factors, Biostatistics, Clinical Significance. Where Are We? Rev Esp Cardiol. 2007;60(12):1220-2.

9. Banerjee TK, Mukherjee CS, Sarkhel A. Stroke in the urban population of Calcuttaand epidemiological study. Neuroepidemiology 2001;20:201-7.

10. Austin MA, King MC, Vranizan KM, Krauss RM. Atherogenic lipoprotein phenotype. A proposed genetic marker for coronary heart disease risk. Circulation. 1990;82:495-506.

11. Togha M, Gheini MR, Ahmadi B, Razeghi PKS. Lipid profile in cerebrovascular accidents Iran J Neurol. 2011;10(1-2):1-4.

12. Goldstein LB. Statins for stroke prevention. Curr Atheroscler Rep2007; 9:305-11.

13. Pandian JD, Sudhan P. Stroke epidemiology and stroke care services in India. Journal of Stroke. 2013;15:128-34.

14. Zhang X, Patel A, Horibe H, Wu Z, Barzi F, Rodgers A, MacMahon S, Woodward M; Asia Pacific Cohort Studies Collaboration. Cholesterol, coronary heart disease and stroke in the Asia Pacific 
region. Int J Epidemiol. 2003 Aug;32 (4):563-72. DOI:10.1093/ije/dyg106. PMID: 12913030.

15. Lindenstrøm E, Boysen G, Nyboe J. Influence of total cholesterol, high density lipoprotein cholesterol, and triglycerides on risk of cerebrovascular disease: the Copenhagen City Heart Study. BMJ. 1994 Jul 2;309(6946):11-5.

doi: 10.1136/bmj.309.6946.11. Erratum in: BMJ 1994 Dec 17;309(6969):1619. PMID: 8044059; PMCID: PMC2542648.

16. Qizilbash N, Duffy SW, Warlow C, Mann J. Lipids are risk factors for ischaemic stroke: overview and review. Cerebrovasc Dis 1992; 2:127-36.

17. Park JH, Kwon HM. Association between metabolic syndrome and previous ischaemic lesions in patients with intracranial atherosclerotic stroke. Clin Neurol Neurosurg 2008; 110: 215-21.

18. Russman AN, Schultz LR, Zaman IF, Rehman MF, Silver B, Mitsias P, et al.A significant temporal and quantitative relationship exists between high-density lipoprotein levels and acute ischaemic stroke presentation.J Neuro Sci 2009;279:53-6.

19. Butterworth RJ, Marshall WJ, Bath PMW. Changes in serum lipid measurements following acute ischaemic stroke. Cerebrovasc Dis 1997; 7:10-3. 